\title{
ALGUNAS NOTAS SOBRE LA LIBERTAD DE EXPRESION DEL ABOGADO CON OCASIÓN DEL EJERCICIO DE SU FUNCIÓN
}

\author{
SOME NOTES ON THE LAWYER'S FREEDOM OF EXPRESSION \\ ON THE OCCASION OF THE EXERCISE OF THEIR FUNCTION
}

Luis Javier GUTIÉRREZ JEREZ

Universidad de Jaén, Real Academia de Jurisprudencia y Legislación de Granada, España

Recibido: 18 Julio 2021 / Aceptado: 31 Julio 2021

\section{Resumen}

Cuando el abogado actúe con ocasión del cumplimiento de su deber de defensa ante los Tribunales, estará ejercitando de forma directa y precisa la libre expresión de pensamientos e ideas como objeto cualificado del derecho a la libertad de expresión, siendo categoría especial derivada de la general contenida en el artículo 20 del texto constitucional. Una de las principales consecuencias del ejercicio de tal libertad de expresión cualificada es, sin lugar a dudas, la posible afectación del honor de terceros, que pudieran verse afectados por la valoración, reflexión, opinión o calificación emitida por un abogado con ocasión del ejercicio de su función.

Palabras clave: Abogacía, Función especial de Estado, Honor, Libertad de expresión

\begin{abstract}
When the lawyer acts in the performance of his duty of defence before the Courts, he shall be exercising directly just the free expression of thoughts and ideas as a qualified object of the right to freedom of expression, being a special category derived from the general category contained in article 20 of the Constitutional text. One of the main consequences of the exercise of such qualified freedom of expression is, without a doubt, the possible affectation of the honour of third parties, that could be affected by the assessment, reflection, opinion or rating issued by a lawyer in the course of the exercise of his function.
\end{abstract}

Keywords: Advocacy, Special function of State, Honor, Freedom of expression 
SUMARIO: I. Libertad de expresión en general y libertad de información, pensamiento e ideas en particular. II. Sobre las características del derecho al honor. III. Ámbitos de la libertad de expresión en la actuación del abogado. IV. La existencia de una libertad de expresión reforzada. V. Bibliografía

SUMMARY: I. Freedom of expression in general and freedom of information, thought and ideas in particular. II. On the characteristics of the right to honor. III. Areas of freedom of expression in the actions of the lawyer. IV. The existence of enhanced freedom of expression. V. Bibliography

\section{LIBERTAD DE EXPRESIÓN EN GENERAL Y LIBERTAD DE INFORMACIÓN, PENSAMIENTO E IDEAS EN PARTICULAR}

Plenamente convencido del efecto protector y de seguridad que produce el derecho a la tutela judicial efectiva por parte de Juzgados y Tribunales al amparo del artículo 24 de nuestra Constitución Española de 1978, de acuerdo con el contenido y de acuerdo con el contenido y alcance del funcional artículo 117 de dicha norma básica del Estado, debo referir lo dispuesto por el legislador en el artículo 542 apartado $2^{\circ}$ de la Ley Orgánica 6/1985, de 1 de julio, del Poder Judicial al afirmar que cuando actúen ante los Juzgados y Tribunales, serán los abogados libres e independientes, se sujetarán al principio de buena fe, gozarán de los derechos inherentes a la dignidad de su función y serán amparados por aquéllos en su libertad de expresión y defensa.

De este precepto obtenemos los cinco perfiles esenciales del ejercicio de la abogacía como función "de Estado":

1. Libertad.

2. Independencia.

3. Buena fe en su ejercicio.

4. Tutela especial de su función.

5. Protección de su derecho a la libertad de expresión y de gestión de la defensa de los intereses sometidos a su especial actuación.

Estas notas definitorias reguladas con ocasión de la reglamentación de la potestad y función jurisdiccional encuentran también su perfecto encuadre en el Estatuto General de la Abogacía Española, objeto de una reciente e interesante reforma operada por Real Decreto 135/2021 de 2 de marzo, que entrará en vigor el próximo 1 de julio de $2021^{2}$ cuando en su trascendental artículo $1^{\circ}$ declara que: 
1. La Abogacía es una profesión libre e independiente, que asegura la efectividad del derecho fundamental de defensa y asistencia letrada y se constituye en garantía de los derechos y libertades de las personas.

2. La profesión de la Abogacía se ejerce en régimen de libre y leal competencia.

3. Los profesionales de la Abogacía deben ser personas de reconocida honorabilidad y, en consecuencia, han de observar una trayectoria de respeto a las leyes, a los principios rectores y valores superiores de la Abogacía, a las normas deontológicas y a las buenas prácticas profesionales.

4. Son principios rectores y valores superiores del ejercicio de la Abogacía los de independencia, libertad, dignidad e integridad, así como el respeto del secreto profesional.

Estos perfiles encuentran un nuevo encuadre frente al defendido o representado ante los Juzgados y Tribunales.

Frente a los primeros, cuando en el artículo 47 apartado $4^{\mathrm{a}}$ del mismo Estatuto General se dispone que el profesional de la Abogacía realizará, con plena libertad e independencia y bajo su responsabilidad, las actividades profesionales que le imponga la defensa del asunto que le haya sido encomendado, ateniéndose a las exigencias técnicas y deontológicas adecuadas a la tutela jurídica del asunto.

Frente a los segundos, cuando el artículo 58 declara que en su actuación ante los Juzgados y Tribunales los profesionales de la Abogacía son libres e independientes, gozarán de los derechos inherentes a la dignidad de su función y podrán solicitar ser amparados en su libertad de expresión y defensa, en los términos previstos por las normas aplicables, amparando en todo caso la Junta de Gobierno Colegial la libertad, independencia y dignidad profesionales del abogado en su actuación ante los Tribunales de Justicia.

Queda descrito así el sobresaliente perfil del ejercicio de la abogacía como cuestión de Estado, como materia entroncada en la tutela activa de derechos fundamentales, recayendo sobre ella el importante deber de hacer creíble la vigencia y plena eficacia del Estado de Derecho.

Todos los ciudadanos contamos con la especial y directa aplicación del artículo 20 de la Constitución Española, en cuanto que se reconocen y protegen los siguientes derechos, sin posibilidad de censura a: 
a) A expresar y difundir libremente los pensamientos, ideas y opiniones mediante la palabra, el escrito o cualquier otro medio de reproducción.

b) A la producción y creación literaria, artística, científica y técnica.

c) A la libertad de cátedra.

d) A comunicar o recibir libremente información veraz por cualquier medio de difusión.

El primero de los derechos de libre expresión, relativo a la difusión de pensamiento, ideas y opiniones incumbe, por supuesto, al abogado. Pero opera en un plano más amplio, centrando perfectamente su condición de ciudadano libre, por encima de su condición de profesional del Derecho.

La libertad de expresión debe distinguirse de la libertad de información como conceptos diferenciados, ${ }^{3}$ aunque en nuestra Jurisprudencia constitucional hay ejemplos

contradictorios respecto a si ambas libertades corresponden a cualquier ciudadano por igual o no. ${ }^{4}$

Por ejemplo, las SSTC 6/1981 de 16 de marzo y 12/1982 de 31 de marzo, en las que se advierte que una y otra libertad corresponden a todos los ciudadanos por igual, parecen diseñar un ámbito igualitario, mientras que otras Sentencias reservan el máximo nivel de protección en el ejercicio de la libertad de información, como categoría cualificada, únicamente a los profesionales en ejercicio de su cargo (por ejemplo, los periodistas), tal y como puede deducirse del contenido de las SSTC 165/1987 de 27 de octubre y 105/1990 de 6 de junio.

En realidad, no existe una postura unificada al respecto, pudiendo considerarse en ocasiones que la libertad de información de un simple ciudadano tiene el mismo nivel de protección que el de un profesional, y en otras, todo lo contrario.

La Jurisprudencia constitucional ha recogido la clave de vinculación entre la libertad de información y la libertad de expresión poniendo de manifiesto que la comunicación de hechos o noticias no se da siempre en un estado "químicamente puro", de forma que, por ejemplo en el ejercicio de profesiones como el periodismo se exige siempre el reconocimiento de una especie de "zona de inmunidad" que la Constitución ha de proteger, no solo para la libre circulación de noticias desde un plano objetivo, sino también para la libre circulación de ideas y de opiniones. ${ }^{5}$ 
Y considera el Tribunal Constitucional que es muy difícil llegar a distinguir netamente entre la libertad de expresión y la libertad para emitir informaciones, ideas y pensamientos, porque toda persona tiene derecho a la libertad de expresión y cuando actúa frente al exterior por razón de una actividad o profesión, realmente se configura una simple especialidad de la general que es aquélla. ${ }^{6}$

Este elemento diferencial me lleva a afirmar que cuando el abogado actúe con ocasión del cumplimiento de su deber de defensa ante los Tribunales, estará ejercitando de forma directa y precisa la libre expresión de pensamientos e ideas como objeto cualificado del derecho a la libertad de expresión, siendo categoría especial derivada de la general contenida en el artículo 20 del texto constitucional.

Una de las principales consecuencias del ejercicio de la libertad de expresión cualificada antes descrita es, sin lugar a dudas, la posible afectación del honor de terceros, que pudieran verse afectados por la valoración, reflexión, opinión o calificación emitida por un abogado con ocasión del ejercicio de su función.

En relación con otros ámbitos, como la representación parlamentaria, que yo considero de igual y nunca inferior trascendencia que el ejercicio de la función de defensa de intereses por el Abogado, se declara por el artículo 71 apartado $1^{\circ}$ de la Constitución Española que "Los Diputados y Senadores gozarán de inviolabilidad por las opiniones manifestadas en el ejercicio de sus funciones", lo que se complementa con el contenido del artículo 21 del Reglamento del Senado de 3 de mayo de 1994 cuando dispone que "Los Senadores gozarán, aun después de haber cesado en su mandato, de inviolabilidad por las opiniones manifestadas en actos parlamentarios y por los votos emitidos en el ejercicio de su cargo".

Exactamente esto es lo que pretendo defender para consolidar el libre y eficaz ejercicio de la abogacía en España: la preservación de un ámbito cualificado de libertad en la crítica y en la decisión, sin el cual, el ejercicio de la función desempeñada por la abogacía podría resultar mediatizado, frustrando el proceso de libertad y responsabilidad que incumbe a la Justicia.

Y la cuestión alcanza una alta cota de significación jurídica cuando, con ocasión del ejercicio de la libre expresión "funcional o profesional" pudiera afectarse otro derecho fundamental como el derecho al honor, bien del cliente, del Tribunal, o la mayor parte de los casos, del Letrado contrario. 


\section{SOBRE LAS CARACTERÍSTICAS DEL DERECHO AL HONOR}

La configuración jurídica del derecho al honor ha sido descrita por el Tribunal Constitucional como lábil, fluida, cambiante y en definitiva dependiente de las normas, valores e ideas sociales vigentes en cada momento, resulta plasmada en la Jurisprudencia constitucional cuando tiene declarado que el honor es un concepto jurídico indeterminado cuya delimitación depende de las normas, valores e ideas sociales vigentes en cada momento, y de ahí que los órganos judiciales dispongan de un cierto margen de apreciación a la hora de concretar en cada caso qué deba tenerse por lesivo del derecho fundamental que lo protege. $^{7}$

Sin embargo, el Tribunal Constitucional ha dado algunos pasos adelante y ha definido el abstracto contenido del derecho al honor afirmando que comprende la buena reputación de una persona, protegiéndola frente a expresiones o mensajes que puedan hacerla desmerecer en la consideración ajena por ir en su descrédito o menosprecio o al ser tenidas en el concepto público por constitutivas de afrenta.

\section{AMBITOS DE LA LIBERTAD DE EXPRESION EN LA ACTUACION DEL ABOGADO}

A continuación, nos referiremos a continuación al ámbito de la libertad de expresión en la actuación funcional del abogado, a) frente a su cliente, b) en relación al Tribunal ante el que actúa, y c) finalmente, frente al Letrado contrario en acto de juicio.

\section{EN RELACIÓN AL DEFENDIDO O REPRESENTADO}

El Estatuto General de la Abogacía ${ }^{8}$ dispone en su artículo 55 que el Abogado, en su condición de garante de la efectividad del derecho constitucional de defensa y de colaborador con la Administración de Justicia, está obligado a participar y cooperar con ella, asesorando, conciliando y defendiendo en Derecho los intereses que le sean confiados por sus defendidos y representados.

Tal conciliación y defensa de intereses debe ejecutarse siempre "en Derecho", es decir, conforme a las normas vigentes que regulan las relaciones jurídicas y actuaciones que sean objeto de conocimiento por parte de los Juzgados y Tribunales, e incluso las que rigen en las relaciones derivadas de la mediación o el arbitraje. 
Su actuación en relación al defendido o representado deberá acogerse en todo caso a lo previsto por el artículo 51 apartado 1 del Estatuto profesional en cuanto que está obligado a no defender intereses en conflicto con aquellos cuyo asesoramiento o defensa le haya sido encomendada o con los suyos propios $\mathrm{y}$, en especial, a no defraudar la confianza de su cliente.

Esta es una cuestión fundamental que condiciona al abogado con ocasión del ejercicio de su función y deposita un enorme peso sobre sus hombros: garantizar el derecho a la tutela efectiva por la vía de la garantía del derecho a una defensa adecuada, sin defraudar la confianza de su cliente, transformando, en suma, el interés particular de éste en el interés directo de la defensa, en aplicación de una especial lex artis profesional.

Simplemente, por esta superior exigencia de principios y valores, no todas las personas pueden o deben ser abogados. Por eso es la profesión jurídica más respetable, difícil y compleja en su ejercicio completo.

Esta especial lex artis comprende un deber de información específica sobre algunos extremos como los aspectos favorables y desfavorables de la actuación procesal, posibles condenas en costas, importes de honorarios que por corresponder a otros profesionales (procurador, notarios, peritos etc...) quedarán fuera de los que devengará el abogado por consecuencia de su actuación, así como información cumplida sobre el estado de procedimiento y de los recursos que podrán interponerse en su caso, contra las Sentencias, Autos y Providencias dictadas en la causa o procedimiento, sin olvidar en ningún momento que el tipo de obligación que se configura en la relación jurídica profesional de abogacía es siempre de medios o simple actividad, y nunca de resultado.

La responsabilidad del Letrado en la construcción argumental de la defensa de intereses es personal y autónoma, de forma que no cabe imputar al cliente por su empeño, insistencia o persuasión las consecuencias del escrito que su representante formule en el ejercicio de su función, ya que, a la luz de los preceptos antes mencionados de su Estatuto profesional, se presume su autonomía e independencia. ${ }^{9}$

Por último, debemos reflejar la importancia del contenido del artículo 12 del Código Deontológico de la Abogacía Española ${ }^{10}$ cuando describe los deberes del Abogado para con sus clientes, centrándolos en el respeto, independencia, máxima información y prohibición del conflicto de intereses con ellos. 


\section{EN RELACIÓN AL JUEZ, TRIBUNAL, FISCAL O ABOGADO DEL ESTADO}

Con ocasión del ejercicio de su función puede el abogado ejercitar su libertad de expresión y libre emisión de juicios de valor de contenido jurídico, aunque los linderos de protección se perfilan con una especial dificultad teniendo en cuenta que, si éste actúa en el ejercicio de una función especialmente protegida, no es menos cierto que la actuación judicial se ampara en lo dispuesto por la Ley Orgánica del Poder Judicial en cuanto a su actuación amparada siempre en la buena fe, en su absoluta independencia y en el deber de rechazar peticiones, incidentes y excepciones que se formulen con manifiesto abuso de derecho o entrañen fraude de ley o procesal. ${ }^{11}$

El ejercicio de la potestad jurisdiccional definida en el artículo 117 de la Constitución Española, debe desarrollarse en todo caso siguiendo las reglas de máximo respeto de su autonomía e independencia que afectará a los Letrados intervinientes en un proceso, así como a sus clientes.

Y si los Jueces o Magistrados competentes se sintieran inquietados o perturbados en tal independencia, deberán poner los hechos en conocimiento del Consejo General del Poder Judicial, dando cuenta ellos al Juez o Tribunal que tuviere competencia objetiva por materia y territorio para incoar el procedimiento adecuado, pudiendo adoptar ellos mismos las medidas oportunas necesarias para asegurar la acción de la justicia y restaurar el orden jurídico, siempre con la cooperación del Ministerio Fiscal. ${ }^{12}$

La libertad de expresión del abogado al tiempo de instaurar su relación funcional con un Juzgado o Tribunal comprende, además del integro respeto de los parámetros de independencia antes descritos, el reconocimiento de que forma parte del deber judicial la promoción de la superior tutela de los derechos e intereses legítimos, tanto individuales como colectivos, sin que en ningún caso pueda producirse indefensión.

En este marco normativo, la libertad de juicio, manifestación y valoración que el Letrado tiene legalmente atribuida hace que deban atenuarse los efectos aparentemente lesivos de manifestaciones que en un determinado momento podrían efectuarse frente a la Autoridad judicial interviniente.

La importante STS 31 mayo 2011 (Rec. 47/2009), declara que "en un sistema democrático, determinadas funciones públicas vienen obligadas a soportar un grado elevado de crítica, sin el cual sería imposible, en este caso, no solo la crítica de las decisiones judiciales, sino la interposición de 
demandas por responsabilidad civil contra magistrados, en las cuales se exige intencionalidad o un grado elevado de negligencia”.

La intencionalidad y falta de diligencia debe presentarse en un alto grado en el Magistrado actuante para que pueda ser admitida a trámite o estimada, en su caso, dejando siempre libre la valoración técnica, incluso cuando sobrepase algunos límites, siempre dentro de la plena justificación del ejercicio de la función desempeñada por el Abogado, puesto que, en caso contrario, nunca podría contar con los instrumentos profesionales que se requieren en la defensa de intereses en juicio.

De esta forma, se valoró la pretendida lesión del derecho al honor del Magistrado competente en un procedimiento judicial civil de ejecución cuando fue acusado de "contumaz, arbitrario y desviado en el ejercicio de su función jurisdiccional", y "de obstinarse o empecinarse en mantener ilegal y reiteradamente la idoneidad de las subastas" en el ámbito del proceso en curso, ${ }^{13}$ declarando el Alto Tribunal que, los derechos fundamentales de libre expresión y de libre ejercicio del derecho de defensa amparan la labor del profesional dentro del contexto profesional-judicial reglado sin que las manifestaciones vertidas pudieran considerarse como ilegítimas, aunque sí fuesen excesivas o incluso no justificadas, sin que pudieran fundamentar una condena por su propia conformación a la luz de lo previsto por la Ley Orgánica 1/1982, de 5 de mayo, de protección civil del derecho al honor, a la intimidad personal y familiar y a la propia imagen.

Y esto fue así, aunque se demostró posteriormente en el curso del procedimiento que las imputaciones realizadas al Magistrado eran falsas y que este actuó en todo momento conforme a Derecho.

Y por último, en este apartado, debemos referirnos a la Sentencia del Tribunal Europeo de Derechos Humanos de 12 de enero de $2016^{14}$ en la que se consideró vulnerado el artículo 10 del Convenio Europeo de Derechos Humanos cuando se condenó penalmente por un delito de calumnias en las diferentes instancias a un abogado por acusar a la Jueza competente en el procedimiento en el cual actuaba profesionalmente el condenado, de mentir y falsear la realidad en resoluciones dictadas en un expediente de dominio.

El Tribunal consideró en este caso, (en el que el abogado era español y el órgano jurisdiccional estaba adscrito a la Audiencia Provincial de Las Palmas de Gran Canaria) que existió una vulneración del mencionado precepto al lesionar el derecho de libertad de expresión que asistía al Letrado actuante, habiendo realizado la acusación base de la condena por medio de escrito procesal, y siendo conocido sólo por las partes intervinientes con ocasión del 
ejercicio de su función, recordando que corresponde también a los Letrados valorar los argumentos defensivos y la pertinencia o no de alegaciones y peticiones que se formulen en el proceso para admitirlas o recurrirlas en ejercicio del deber de defensa de los intereses de sus clientes, sin perjuicio del deber judicial de acordar las medidas admisibles en cada caso concreto.

\section{FRENTE AL LETRADO CONTRARIO}

El nuevo Estatuto General de la Abogacía exige en su artículo 59 apartado $1^{\mathrm{o}}$ que los profesionales de la Abogacía deben mantener recíproca lealtad y respeto mutuo, con lo que se sientan dos límites objetivos que han de marcar el contenido y ejercicio de la libertad de expresión y valoración con ocasión del ejercicio de sus funciones en juicio y fuera de él.

Y junto a estos dos deberes estructurales, exige el mismo artículo 59 apartado 2-b) que el Abogado actuante debe mantener el más absoluto respeto por el profesional de la Abogacía de la parte contraria, "evitando toda alusión personal en los escritos judiciales, informes orales y cualquier comunicación oral o escrita".

Como fijación de esta exigencia normativa y funcional debemos poner de manifiesto que la Sala $1^{\text {a }}$ del Tribunal Supremo, en STS 3 de septiembre de 2015 (Rec. 106/2014) condenó a un abogado por las expresiones injuriosas que, en el seno de procedimiento judicial, profirió al abogado contrario, al concluir que concurrían insultos y ofensas que no se encuentran amparadas por la libertad de expresión ni por el ejercicio del derecho de defensa.

La indemnización por el daño causado se fijó en la cantidad de 6.000 euros frente a los 60.000 euros solicitados por las expresiones utilizadas por parte del Letrado condenado al dirigirse a su compañero, al que le llamaba, entre otras cosas, "Geppetto, el hábil carpintero que fabricó a Pinocho, muñeco que cuando mentía le crecía la nariz" o la comparación constante con la imagen gráfica del cartel de la película "El Padrino" (que llegó a exhibir), con hilos manipulables, en evidente conexión mafiosa del abogado y sus clientes.

Tal y como la misma Sala puso de manifiesto, resultó relevante, por una parte, la reiteración de la conducta que culmina con las expresiones utilizadas por el demandado y por otra, la falta de difusión de tales expresiones dado que se produjeron en sede judicial, pues la difusión en sí misma no constituye requisito necesario para apreciar la intromisión, pero sí ha de ser tenida en cuenta a la hora de valorar la intensidad del daño causado. 
Y quedó sentado por la Sala el criterio que considera que el contenido de la libertad de expresión de los letrados en el proceso "es específicamente resistente e inmune a restricciones en su ejercicio fuera de la prohibición de utilizar términos insultantes, vejatorios o descalificaciones gratuitas, ajenas a la materia sobre la que se proyecta la defensa". ${ }^{15}$

\section{LA EXISTENCIA DE UNA LIBERTAD DE EXPRESIÓN REFORZADA}

Tal y como ha quedado acreditado, el Tribunal Constitucional ha delimitado un perfil de la libertad de expresión de los Abogados por razón de su función, que está especialmente protegido frente a las restricciones ordinarias que operan en el ámbito material y funcional de otros derechos y libertades. ${ }^{16}$

La abogacía ejerce una función que anteriormente calificamos "de Estado", en cuanto que desarrolla y ejecuta el derecho-deber de defensa efectiva como medio de ejecución del derecho a la tutela judicial efectiva, sobre todo a la luz de la consideración que la propia Ley de Enjuiciamiento Civil realiza en su artículo 31, cuando dispone que los litigantes serán dirigidos por abogados habilitados para ejercer su profesión en el Tribunal que conozca del asunto, sin que pueda proveerse ninguna solicitud que no lleve la firma de abogado ${ }^{17}$ fuera de los muy excepcionales supuestos que el mismo precepto enumera.

La expresión "libertad de expresión reforzada" procede del contenido argumental integrado en el Fundamento Jurídico $4^{\circ}$ de la Sentencia del Tribunal Constitucional 113/2000, de 5 de mayo en la que se declara que dicha libertad, de la que son titulares los Abogados en el ejercicio de su función, trae su causa de la inmediata conexión con la efectividad de otro derecho fundamental como el "derecho a la defensa y a la asistencia de letrado" contenido en el artículo 24 apartado $2^{\circ}$ de la Constitución Española.

En consecuencia, la libertad de expresión de un Letrado en el ejercicio de sus funciones procesales, como cooperadora de la función jurisdiccional misma, debe valorarse siempre desde una perspectiva de excepción, y como ha declarado el Tribunal Constitucional en Sentencia 205/1994 de 11 de julio, "se trata de una manifestación especialmente inmune a las restricciones que en otro contexto habrían de operar".

De las categorías de intromisiones lesivas que justificarían el ejercicio de una acción de responsabilidad civil, reflejadas en el artículo 7 de la Ley 1/1981de 5 de mayo, de Protección Civil del Derecho al Honor, a la Intimidad Personal y Familiar y a la Propia Imagen, debemos destacar las contenidas en los apartados tercero, sexto y séptimo como encuadrables de forma más 
probable en el ejercicio del derecho de defensa efectiva por parte de un Abogado:

- La divulgación de hechos relativos a la vida privada de una persona o familia que afecten a su reputación y buen nombre, así como la revelación o publicación del contenido de cartas, memorias u otros escritos personales de carácter íntimo.

- La revelación de datos privados de una persona o familia conocidos a través de la actividad profesional $\mathrm{u}$ oficial de quien los revela.

- La imputación de hechos o la manifestación de juicios de valor a través de acciones o expresiones que de cualquier modo lesionen la dignidad de otra persona, menoscabando su fama o atentando contra su propia estimación.

\section{BIBLIOGRAFÍA}

GÓMEZ DE LA ESCALERA, C. (2018), La libertad de expresión reforzada del abogado, Valencia

PUERTA LUIS, L. R. (1992), "Libertad de expresión y opinión pública", XII Jornadas de Estudio sobre los derechos fundamentales y libertades públicas, Ministerio de Justicia, Madrid, vol. I.

SANTAOLAYA LÓPEZ, F. (1992), "Jurisprudencia del Tribunal Constitucional sobre la libertad de expresión", Revista de Administración Pública, $\mathrm{n}^{\circ} 128$.

NOTAS

1 Catedrático de Derecho Civil de la Universidad de Jaén y Académico Correspondiente de la Real Academia de Jurisprudencia y Legislación de Granada.

2 Así lo establece la Disposición final cuarta del Real Decreto 135/2021 de 2 de marzo (BOE $n^{\circ}$ 71 de 24 de marzo de 2021).

3 Vid. PUERTA LUIS, L. R. (1992), "Libertad de expresión y opinión pública”, XII Jornadas de Estudio sobre los derechos fundamentales y libertades públicas, Ministerio de Justicia, Madrid, vol. I, p. 1041.

4 Son muy interesantes las valoraciones que efectúa al respecto SANTAOLAYA LÓPEZ, F. (1992), "Jurisprudencia del Tribunal Constitucional sobre la libertad de expresión”, Revista de Administración Pública, no 128 , pp. 186 y 187.

5 STC 171/1990, de 12 de noviembre en su Fundamento $10^{\circ}$.

6 STC 171/1990, de 12 de noviembre en su Fundamento $10^{\circ}$, STS 223/1992, de 14 de diciembre, especialmente en su Fundamento $1^{\circ}$, STS 123/1993, de 19 de abril en sus Fundamentos $2^{\circ}$ y $3^{\circ}$ y STC 232/1993 de 12 de julio en su Fundamento $1^{\circ}$.

$7 \quad$ STC 223/1992, de 14 de diciembre.

8 Real Decreto 135/2021 de 2 de marzo, BOE n 71 , de 24 de marzo. 
Esta cuestión ha sido valorada en algunas resoluciones judiciales desde una perspectiva doble procesal y constitucional. Así, por ejemplo, la STS 30 junio 2004 (Rec. 2898/1999) o la STC55/2004 de 19 de abril en la que se estudia el problema de determinar si los términos de una carta dirigida a una empresa por parte del abogado representante de un empleado reclamante, se limitaba a formular una queja por violaciones de Leyes o Reglamentos, plasmada en ideas, juicios o relatos amparados por el art. $20 \mathrm{CE}$ o si, excediendo de tales objetivos, se incluían manifestaciones merecedoras de reproche por atacar a otros bienes o derechos. Según el Tribunal Constitucional, las instrucciones que un cliente da a su abogado no determinan que sea imputable a aquél el contenido del escrito que el abogado elabora en el ejercicio de su tarea profesional.

10 Aprobado por el Pleno del Consejo General de la Abogacía Española el 6 de marzo de 2019.

11 Vid. artículos 10 a 12 Ley Orgánica 6/1985, de 1 de julio del Poder Judicial.

12 Vid. artículos 14 y 15 Ley Orgánica 6/1985, de 1 de julio del Poder Judicial.

13 El recurso de casación interpuesto tuvo su origen en una demanda de responsabilidad civil contra jueces y magistrados sobre la base de lo previsto en los art. 411 y ss. de la Ley Orgánica de Poder Judicial en la que se reclamaba indemnización patrimonial fundada en la actuación negligente del magistrado por no acceder a la nulidad de las subastas celebradas en la ejecución provisional de sentencia de un procedimiento judicial declarativo de menor cuantía seguido en el año 1996.El Magistrado afectado alegó que no hay ofensa más grave para un miembro de la Carrera judicial que achacarle la comisión de un delito de prevaricación, sin prueba alguna de que su hubiera vulnerado el correcto ejercicio de su función judicial al no acceder a declarar la nulidad de las subastas celebradas en ejecución provisional de sentencia, habiendo señalado a las partes el derecho que tenían de interponer los correspondientes recursos que procediesen en Derecho.

14 Asunto RODRÍGUEZ RAVELO c. ESPAÑA (Demanda $n^{\circ}$ 48074/10), Sentencia Tribunal Europeo de Derechos Humanos de 16 de enero de 2016.

15 Criterio también mantenido anteriormente por la STS 31 mayo 2011 (Rec. 47/2009).

16 Puede consultarse a GÓMEZ DE LA ESCALERA, C. (2018), La libertad de expresión reforzada del abogado, Valencia, p. 45 a 48.

17 Dicha Ley tiene previstas algunas excepciones especiales que recoge el mismo artículo 31:a) La tramitación de los juicios verbales cuya determinación se haya efectuado por razón de la cuantía y ésta no exceda de 2.000 euros y la petición inicial en los procedimientos monitorios.b) Los escritos que tengan por objeto personarse en juicio, solicitar medidas urgentes con anterioridad al juicio o pedir la suspensión urgente de vistas o actuaciones, siempre con un carácter extraordinariamente limitado en garantía del derecho a tutela efectiva de los Tribunales. 